\title{
Forest Management for Enhancing Ecosystem Services in the Climate Change Scenario of Bangladesh
}

\author{
Ajit Kumar Rudra \\ Patuakhali Coastal Forest Division, Forest Department, Bon Bhaban, Bangladesh
}

Copyright $\bigcirc 2016$ by authors, all rights reserved. Authors agree that this article remains permanently open access under the terms of the Creative Commons Attribution License 4.0 International License

\begin{abstract}
Ecosystem services of forests are essential for human life. As the human population increases, the demand for ecosystem services also increases and thereby the amount of forest is declining, taking their ecosystem services with them and leaving the remaining forests and their services more significant and scarce. The once biodiversity rich forests of Bangladesh have undergone massive deforestation and degradation due to high population pressure and lack of proper management. In recent years there has been a substantial shift in emphasis in forest management from maximizing yield towards maximizing sustainability through increased participation of local population, conserving biodiversity, and maintaining ecosystem services. New forest management systems are added to address climate change scenario, such as agroforestry, strip plantation, participatory forestry on encroached forest, community based mangrove afforestation on newly accreted land in the coastal area and conservation area management to preserve wildlife habitat and biodiversity. This paper presents a brief account of ecosystem services of forests that are crucial for climate change adaptation and mitigation. Some studies related to ecosystem services interaction with their management implications are reviewed; valuation of ecosystem services is studied and recommends management techniques to ensure more effective conservation of existing forest and biodiversity resources are recommended. Conservation area management proved as efficient, successful and cost-effective tool for maintaining ecosystem services in the climate change context, as they often protect the last remaining large areas of natural habitats. Increasing the protected area network and improving management techniques can enhance the resilience of ecosystem to climate change and safeguard vital ecosystem services.
\end{abstract}

Keywords Ecosystem Services, Forest Management, Climate Change, Protected Areas, Collaborative Management

\section{Introduction}

Ecosystem services of forests are essential for human life as they deliver multiple services in terms of life support (nutrient cycling and soil formation), provisioning (timber, fuelwood, food, fresh water, medicine etc.), regulating (carbon sequestration and climate regulation, flood control, water purification, pest and disease control etc.) and cultural and social functions (recreation, ecotourism etc.). As the human population increases so does the demand for ecosystem services. In many places on earth the sustainability of these services is threatened or is declining. As the demand for ecosystem services is rising, the amount of forest is declining, taking their ecosystem services with them and leaving the remaining forests and the services that they provide more significant and scarce. In the last three centuries alone, forests globally have been reduced by approximately $40 \%$. Individual ecosystem services are also part of the interdependent web within a forest. Reducing one service can have dramatic effects on the other strands of the web. If a forest is managed for timber without forethought to its other ecosystem services, this may result for example in a decrease in its carbon sequestration capacity or its wildlife protection value [14]. So there is a need for conserving or enhancing ecosystem services in such a way that reduces negative trade-offs or that provide positive synergies with other ecosystem services.

Accordingly, various models of forest management systems have evolved over time. They range from "exploitive" to "back-to-nature", with all intended to satisfy the diverse human demands for the services provided by the forests [7, 9, 16]. Contemporary sustainable forest management aims to ensure that goods and services derived from forests meet present-day needs while at the same time securing the forests' continued viability and contributions to long-term development. As such, forest management itself requires prudent management in order to conserve essential ecosystem services such as soil fertility and water quality. As well as this, additional supporting and cultural services such as carbon sequestration, maintenance of biodiversity, or recreational values also need consideration. Our understanding of these services is still limited. Without an understanding or appreciation of the values that ecosystem 
services have on our quality of life, it is difficult to take the steps necessary to protect them. As forests continue to disappear the value of their remaining services becomes even more significant. Understanding and awareness of the complex interactions of the apparent forest ecosystem services is crucial to their management and understanding their link to water resources [3].

\section{Forests Scenario of Bangladesh}

Bangladesh has 2.53 million hectares of forest land (which is about $17.49 \%$ of the total land) of the country, including all the public forest land, unclassed state forests and village forest [6]. Existing forest types of Bangladesh are categorized as hill forests (1.40 million ha.), plain land sal (shorea robusta) forests ( 0.12 million ha.), mangrove forest (0.74 million ha.) and homesteads (0.27 million ha.). Bangladesh Forest Department manages 1.53 million hectares of forested land including all mangrove forests, sal forests and 0.67 million ha of hill forests in the Chittagong Hill Tracts, while the rest 0.73 million ha of hill forests in the Chittagong Hill Tracts (CHTs) called unclassed state forests are managed by district civil administration [15] (Table-1).

Table 1. Total Forest Land and Forest Area managed by Forest Department of Bangladesh

\begin{tabular}{|c|c|c|}
\hline Category of Forests Area & Area (Million ha) & Percentage \\
\hline Forest Department managed forests & 1.53 & 10.54 \\
\hline Unclassed state forests & 0.73 & 5.07 \\
\hline Village forests & 0.27 & 1.88 \\
\hline Total & 2.53 & 17.49 \\
\hline
\end{tabular}

Forest Area managed by Forest Department of Bangladesh

\begin{tabular}{|c|c|c|}
\hline Forest types & Area (Million ha) & Percentage \\
\hline Hill forests & 0.67 & 4.65 \\
\hline Natural mangrove forests & 0.60 & 4.09 \\
\hline Mangrove plantations & 0.14 & 0.97 \\
\hline Plain land sal forests & 0.12 & 0.83 \\
\hline Total & 1.53 & 10.50 \\
\hline
\end{tabular}

The hill forests of Bangladesh classified into tropical wet evergreen and tropical semievergreen forests are biodiversity rich, located in the mega biodiversity north-eastern subcontinent. The Sundarbans, the world largest mangrove forests, is the home of Royal Bengal Tiger [6]. Mangrove plantations have been raised along the coast. Sal forests, classified as tropical moist deciduous forests, have become severely degraded, the deforested forest lands have been brought under social forestry based on participatory benefit sharing agreement that have been signed with participants as per the social forestry rules 2004. As representatives of the country's four bio-geographic zones, 27 national parks and wildlife sanctuaries have been established as per the provision of the Wildlife Act of 1974.
Over the period the natural forests have been depleted and as per the UNDP supported National Biodiversity Strategy and Action Plan [11] of the Government of Bangladesh, the country's forest cover has declined from 10 to $6 \%$ of the total geographic area. The evergreen and semievrgreen hill forests could not be protected mainly due to the lack of resources and clear felling of natural hill forests for raising commercially valuable plantations such as teak, which resulted in loss of ecologically diverse forests. Plantation forests declined substantially particularly after 1985 and thus could not compensate for the high rate of deforestation and degradation of natural forests.

The private forests (e.g. sal forests of Madhugarh and Bowalgarh) under the management of local rulers and landlords though brought under the control of forest department by enacting the State Acquisition and Tenacy Act, 1953, could not be effectively protected mainly due to lack of their proper reservation and management under the forest Act. Being near to the urban centers with dense population, sal forests have come under large scale encroachment mainly for cultivation and settlement. The forests not under the management of Forest Department (e.g. unclassed state forests in Chittagong Hill Ttracts) actually do not have good forest cover and the current presence of grasses indicate the extent of site degradation that has taken place over time. In a land-scarce country the diversion of forest land for non-forestry purposes still continues. Ali, $2002 \mathrm{~b}$ [1] describes that about 62000 ha of national forest land have been encroached up to December 1980 and more than 88000 people were living inside forests.

Despite numerous challenges, a number of achievements have been made by the Bangladesh Forest Department as social forestry program has been successfully implemented since 1981 when community forestry was started in northern part of Bangladesh by involving rural poor. This social forestry program is now institutionalized through legal reform. The Forest Act 1927 was amended in 1989 and 2010 to endorse the concept of social forestry within legal framework. After amendment of law, social forestry rule 2004 was framed. Benefit sharing mechanism of the stakeholders are clearly defined in this rule.

For instance, during 2000-09 nearly 84000 participants received Tk. 1,250 million in total as benefits of social forestry program that were implemented by Forest Department. Additionally a large number of rural poor was engaged in raising social forestry plantations and received minimum wages for their labour. Social forestry has become a people's movement and is now being expanded as private tree growing and also on non-forest khas lands. Besides social forestry program, co-management is now introduced successfully as rehabilitation and conservation strategy for 19 Protected Areas in Bangladesh where co-management councils and committees, formed under gazette notification, are protecting forests and wildlife in gainful partnerships with local community. 


\section{Climate Change Impact}

Bangladesh is one of the most vulnerable countries to climate change, variability and extreme events. The country is suffering from serious impacts because of low lying delta and dense population. It experiences frequent natural disasters such as cyclones, tidal charge, flood, drought and erratic rainfall which cause immense loss of life and livelihoods and colossal damage to infrastructure and economic assets especially of poor people [12]. The impacts of climate change on biodiversity of Bangladesh are incalculable as large part of coastal region of the country is under threat of being inundated. Climate change has already produced shifts in the distribution of some species such as amphibians, grasses, migratory birds and butterflies. Forests and agricultural systems are vulnerable to increased incidents of disease and pest outbreaks as a result of changing climatic conditions. Climate change impacts are expected to be substantial on the country's predominantly agrarian economy, as a large majority of its population is reliant on land based primary production as a major source of income. Forest ecosystems are generally able to tolerate some level of climate change and so will continue to persist in short term as they have done in the past. However, in the long term it is not known whether their resilience will be sufficient enough to tolerate further anthropogenic climate change.

\section{Ecosystem Services for Climate Change Adaptation and Regulation}

The forest ecosystems provide socioeconomic and ecological services in terms of life supporting; provisioning and regulating functions and so have tremendous impact on the climate change adaptation of local community. The role of forests in carbon cycle is vital as they account for approximately $80 \%$ of $\mathrm{CO}_{2}$ exchanged between land and atmospheres through the process of photosynthesis. As terrestrial and aquatic vegetation grow, the carbon is stored in biomass by converting $\mathrm{CO}_{2}$ and water (by using solar energy) into sugars and oxygen (released through leaves). However forests that are growing (increasing in biomass) will absorb more $\mathrm{CO}_{2}$ than they release. So the climate change mitigation role of forests ecosystems in terms of sequestration and storage potential of the $\mathrm{CO}_{2}$ depend on growing, conserving and sustaining them.

Climate change adaptation is important for improved ecosystem management, ensuring economic and climate change resilience benefits to local community. The climate change adaptation role of a forest ecosystem stems from the fact that local people depend not only nearby ecosystems for their resilience functions, but also for their livelihoods, thereby reducing their vulnerability by providing a coping mechanism. A large portion of the landscape population around many important ecosystems such as Sundarbans is dependent on climate-dependent activities such as fisheries, agriculture and forestry.

Forests provide livelihoods to local economy. Additional benefits mobilized through off-PA activities including value chain development and alternative income generation activities generate both wage and self-employment. A number of livelihood opportunities can be identified and conservation linked interventions designed for providing alternative income to local community (such as home gardening, poultry farming etc.) in order to reduce extractive harvesting from ecosystems. Value chain mapping can be done by identifying all possible actors and factors. The increased population with few alternative livelihood opportunities poses a serious threat to many ecosystems.

Livelihood dependence of local people on forest ecosystems is high and in future this dependence will increase. There are a large number of people directly involved with resource extraction from forest ecosystems. The pressure for resource extraction has increased tremendously as the number of collectors has increased manifold over the last decades, resulting in huge reduction in per capita resource collection. Land based value chains (e.g. fisheries and tree nursery) may be designed for their implementation as climate change adaptation initiatives in the landscape villages.

The country's forest ecosystems are primary producers and protectors of various natural and human resources. Forests not only maintain and improve moisture regime and provide clean air but also produce humus and maintain soil fertility. These are vitally important for maintaining and regulating water flows and sub-soil water regimes because of thick humus layer, loose soil and soil retaining power of tree roots. The county's forest ecosystems and their natural process recharge aquifers and maintain water regimes and moderate the impact of natural disasters including flood, drought and cyclone, thereby ensuring food security and regulating climate change. Water and fertile top soils are the two main prerequisites of the country's food security, are irrevocably linked with forests and their watershed conservation functions. Forest reduces air temperature and wind velocity and increases relative humidity that helps in reducing evaporation, and in increasing moisture balance in adjoining agricultural fields, creating a favourable climate for better productions.

Natural vegetation in forests is the prime conserver of soil and the provider of nutrients and humus. Many forests are named after the rivers originating and flowing from them (Mathamuhuri and Sangu headwater Reserve Forests). Forests are living sponges of water which they hold in vast amount in the soil they shade, in their trunks, branches and leaves and via transpiration in the air around and above them. The thermal stability of water stored in the forests of the subcontinent in general and Bangladesh in particular is the fundamental stability factor of subcontinental climate. So the unique and representative ecosystems and biotypes should be effectively preserved and allowed to progress to their climax vegetation level as maximum biodiversity is manifested only in a climax condition. 
Water flow, both quantitative and qualitative, may be regarded as the single greatest function of forests, since most of the country's river and wetlands emanate from forests that constitute the upper catchment of these waterbodies. These wetlands are now under serious threat due to encroachment, over extraction and environmental pollution. However beneficial effects of forests and wetlands depend on their size, location, composition, structure etc.

Forests supply a wide range of non-timber goods and services, which are given high priority in forest sector policy but their real importance is not reflected in the revenue they generate; indeed most of the services and many non-timber forest products are supplied free of charge. Cultural values of forests including recreation and ecotourism and forests being abode of cultural festivals (Rash Mela in the Sundarbans Reserve Forests) and temples (e.g. Sitakunda temple inside the Sitakundu reserve forests) culminate in spirituality. These events provide recreation and aesthetic refreshments for people.

\section{Management Interventions towards Forest Ecosystem Conservation in Bangladesh}

Under the process of paradigm shift of contemporary forest management in Bangladesh, Social Forestry, a new forest management practice have been introduced with a view to meet the forest product requirements of local population. It also aimed to reverse the process of forest degradation and combat deforestation by involving people in plantation programme and benefit sharing especially to improve the socio-economic condition of the rural people. By taking support of the development partners (Asian Development Bank and World Bank), a number of development projects were implemented in Bangladesh. These development initiatives had contributed in combating deforestation and forest degradation. Among different afforestation and reforestation initiatives, woodlot, agro-forestry and strip plantation were successful components to combat deforestation and forest degradation in the country.

Unique types of forests and fragile ecosystem are being conserved and protected by declaring them as protected areas under the Wildlife Conservation Act, which entitled the forest department to establish protected areas such as national parks, wildlife sanctuaries, game reserves etc. Now 28 protected areas have been established in Bangladesh covering an area of about 2,68,961 hectares which is ten percent of total forest land in the country and contributes to the conservation and protection of unique types of forests and fragile ecosystems. While low forest cover becomes the common characteristic of many Protected Areas in Bangladesh due to livelihood dependency of millions of people, co-management is now introduced successfully as rehabilitation and conservation strategy for Protected Areas in Bangladesh.

\section{Studies Related to Ecosystem Service Interactions and Their Management Implications}

A study on "Evaluation of management strategies in Chittagong Hill Tracts (CHT's) watershed" was carried out to identify a potential and best compromise solution for the sustainable management of mountain watershed of Bangladesh [2]. A combined approach of criteria and indicators (C\&I) and Multi-Criteria Analysis (MCA) have been used to formulate a clear and transparent picture of the current situation of the selected watershed area. The preferences of key informants have been elicited in order to identify the relevance for the six principles policy planning, economic income, ecological maintenance, risk factors, livelihood of people and management planning and their criteria respectively. Within the Integrated Watershed Resource Management (IWRM) framework six management strategies have been designed with local experts out of 46 different activities in order to overcome the current problems in the project area. The management strategies such as bio-diversity conservation strategy, flood control strategy, soil and water quality conservation strategy, indigenous knowledge conservation strategy, income generating watershed conservation strategy and landscape conservation strategy have been assessed qualitatively on their potential to improve the current situation according to each verifier of the C\&I set. The Analytical Hierarchy Process (AHP) is used for identifying the best management strategy in the context of the pairwise evaluation of each management strategy for all criteria of the C\&I set and the different preferences of the stakeholder groups. The bio-diversity conservation strategy for watershed management is performing best according to overall priorities of IWRM framework among six management alternatives. The identified management strategy has the potential to improve the existing current problems of mountain watershed in CHT's by multilevel institutions through creating awareness about IWRM among local people. As a consequence, major problems of language barriers, ownership right of land, threatened watershed, flash flood, soil erosion and water quality maintenance are expected to be managed. The results of the study indicate that the combined approach of C\&I and MCA would be a systematic guideline for CHTs stakeholders to proceed for managing existing environmental problems by effective land management, establishment of eco-village, conservation of bio-diversity hotspot and water quality maintenance. In addition, local people involvement might be ensured for forest conservation by providing high subsidies.

Casemus et al, 2014 [4] analyzed trade-offs, synergies and drivers among timber production, carbon sequestration and water yield in Pinus elliotii forests in Southeastern USA in order to identify effective forest management practices. They 
used available data from 377 permanent plots from the USDA Forest Service Forest Inventory and Analysis Program for 2002-2011, and a forest water yield model to quantify provision levels and spatial distribution and patterns of carbon sequestration, timber volume and water yield for Pinus elliotii ecosystems in North Florida, USA. A ranking-classification framework and statistical analyses were used to better understand the interactions among ecosystem services and the effect of biophysical drivers one ecosystem service bundles. Results indicated that increased biomass reduced water yield but this trade-off varied across space. Specific synergies, or acceptable provision levels, among carbon sequestration, timber volume and water yield were identified and mapped. Additionally, stand age, silvicultural treatment, and site quality significantly affected the provision level of, and interactions among, the three ecosystem goods and services. There has been increased interest in forest $\mathrm{C}$ sequestration and timber production because of their influential effects on climate change and in providing energy alternatives and other market and profit opportunities. At the same period, water yield is a highly valued service by society [18]. Thus, the framework developed in the study (as shown below) can be used to assess, map and manage subtropical ecosystems for optimal provision of these three and other services. The following diagram shows the ecosystem service interaction classification (IC) framework. The order, or sequence, of the three digits in the IC is always carbon sequestration as the first digit, timber the second digit, and water yield as the third. Three provision level classes are produced for each of the three ecosystem services, which were coded 3, 2, and 1, representing high, medium, and low provision levels, respectively according to Jenk's natural breaks algorithm [4].

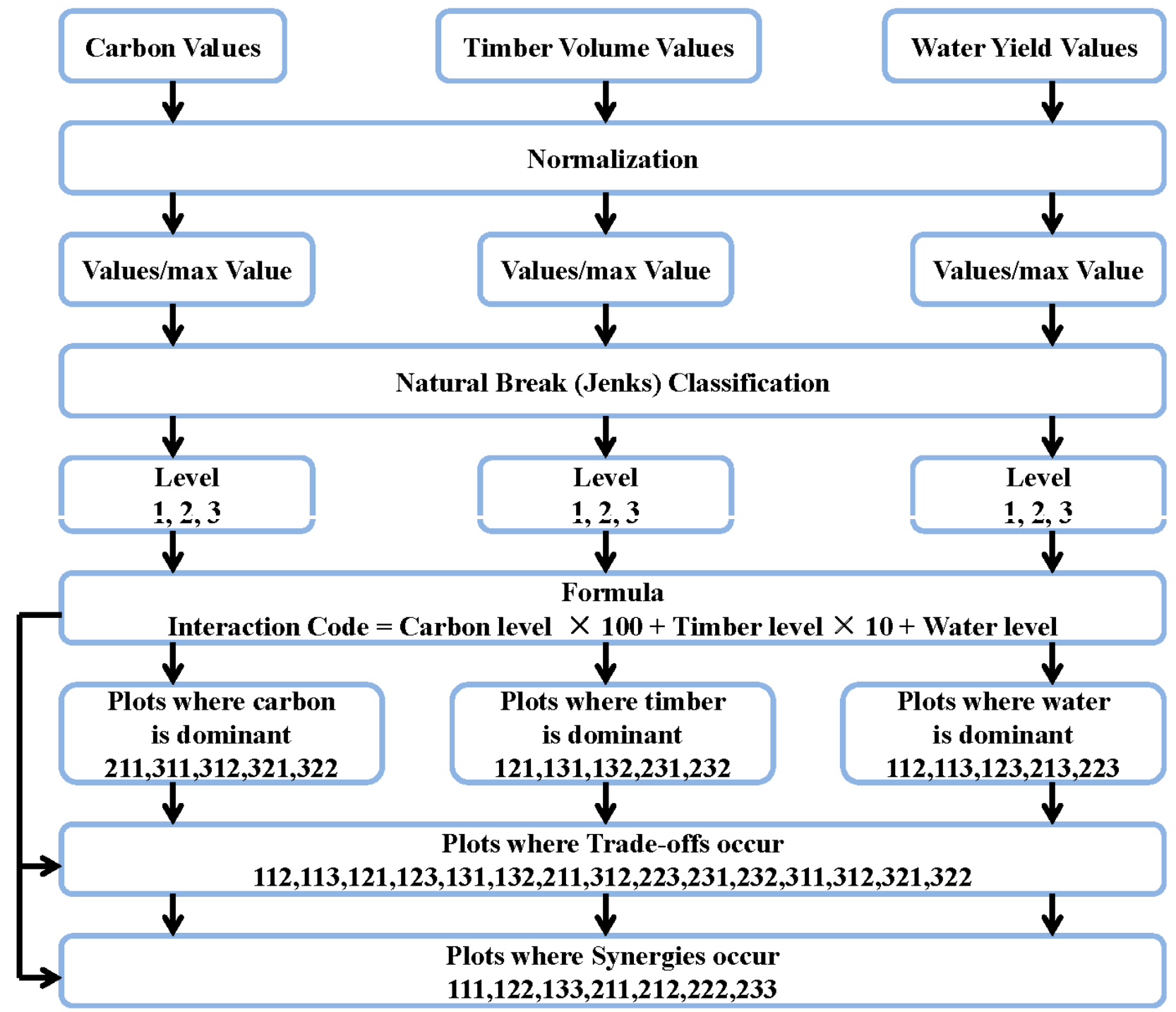




\section{Valuation of Ecosystem Services}

Forest ecosystem services are characterized as important to human beings, but not expensive like other services e.g. water is clearly more important to people's livelihoods than diamonds, but it is cheap while diamonds are expensive. This is because prices are controlled by supply and demand, and the supply of water (at least in Marshall's time and place) was so large that it exceeded the quantity that could be demanded at any price. Nowadays, increasing demand for and scarcity of water increases water prices, though not at the same scarcity level as for diamonds. The price of important forest services like watershed protection or pollination might only rise as soon as scarcity begins to prevail, creating a willingness to pay for these services on behalf of economic agents.

Forest ecosystem services can be grouped under use and non-use, direct and indirect values. Examples of direct use values in forests include timber, non-timber products and non-commodity benefits such as forest recreation. Indirect use values include the services of forests in protecting watersheds, fisheries and carbon storage. Non-use (option, existence and bequest) values include values attached to forests merely because they exist, or values attached to maintaining them for future options to use them or as bequests to coming generations. Again there is a distinction between local, regional, national, and global values associated with forests depending on who captures the benefits:

(a) Local values generally refer to goods and services where the actual forest user derives the benefits (e.g. forest products collected by a community for sale or own consumption; timber harvested and sold by a logger; the recreation experience of a family).

(b) Regional values can be defined (e.g. at the state or provincial level) or by the nature of a forest-service link (e.g. downstream users of a watershed).

(c) National values refer to values that are captured beyond the local forest user (e.g. wildlife habitat protection for national tourism or hydroelectric generation).

(d) Global values refer to those received by individuals living outside the sovereign nation producing them (e.g. carbon sequestration).

It is generally assumed that the incomplete valuation of the forest goods and services is one of the main reasons contributing to deforestation and forest degradation [8]. If the total economic value of forests was really taken into account then people would recognise their importance and better protect and manage forest ecosystems. Valuation results can also be used in determining or influencing pricing, land use and incentive policies [13] or to influence or justify land-use and natural resource management decisions, including in terms of fiscal accountability and public support and internalisation of costs. Forest valuation is therefore a tool that can provide society and decision-makers with information for deciding among alternatives or upon preferred combinations of possible interventions [10].There are six major ecosystem service economic valuation techniques when market valuations do not adequately capture social value as described by Farber et al, 2002 [5]. These are:

1) Avoided Cost (AC): Services allow society to avoid costs that would have been incurred in the absence of those services; flood control avoids property damages or waste treatment by wetlands avoids health costs.

2) Replacement Cost (RC): services could be replaced with man-made systems; natural waste treatment can be replaced with costly treatment systems.

3) Factor Income (FI): services provide for the enhancement of incomes; water quality improvements increase commercial fisheries catch and incomes of fishermen.

4) Travel Cost (TC): service demand may require travel, which costs can reflect the implied value of the service; recreation areas attract distant visitors whose value placed on that area must be at least what they were willing to pay to travel to it.

5) Hedonic Pricing (HP): service demand may be reflected in the prices people will pay for associated goods; housing prices at beaches exceed prices of inland homes.

6) Contingent Valuation (CV): service demand may be elicited by posing hypothetical scenarios that involve some valuation of alternatives; people would be willing to pay for increased fish catch in the forest area.

Each of these methods has its strengths and weaknesses. Also, each service has an appropriate set of valuation techniques. Some services may require that several techniques be used jointly. For example, the recreational value of an ecosystem will include not only the value that visiting recreationists place on the site (TC), but the increased incomes associated with site use.

\section{Challenges and Opportunities}

Ecosystem services are by definition determined by the interaction between ecological and social systems, because only ecosystem processes that contribute to the fulfillment of human needs are ecosystem services. This requires forest managers to work with scientists from other disciplines when trying to understand how ecosystems contribute to human welfare.

Attempts to use the concept to quantify management consequences on ecosystem functions and resulting changes in the economic value of goods and services may oversimplify complex interactions in social-ecological systems. For example, monetization of ecosystem services may result in better management of some services, but still underestimates the value of preserving ecosystem functions 
for long-term sustainability. Existing knowledge, institutional and financial capacities poses great challenges across the regions at various scales to increase the ecosystem management potential. The prevailing knowledge and capacity gaps could be strengthened by expanded research capacities, improved sharing of knowledge, knowledge mobilization, community participation, responsibility sharing and trans-boundary initiatives. A platform, which integrates knowledge and data on all ecosystem types and within similar time frames, is required to assess the ecosystem dynamics at national and regional levels.

Ecosystem service offers the forest managers a unique opportunity to act as promoters for the understanding of how to conserve and sustain benefits gained from forests. Well managed forests serve as a green belt; protect coastal areas from natural calamities, prevent erosion on hillsides, reduce the risk of landslides and reduce the downstream flood risk, improve the soil quality, fertility and crop productivity and thereby ensure food security. The higher opportunity cost of land on small farms may increase the cost of carbon sequestration by community plantations more than that of agricultural production [17]. Climate change funding presents an opportunity to expand sustainable forest management. Such funding presents an opportunity for governments to improve implementation of management interventions for biodiversity conservation and to strengthen forest-based climate change adaptation.

The main drivers threatening Bangladesh's protected forest areas are high population and poverty which results in lack of access to land or employment opportunities as well as lack of access to affordable building materials and cooking fuels. Lack of government financial and human resources to adequately manage the current and expanding protected area system are the additional drivers. Government budgets are limited, often prioritizing more immediate challenges in disaster relief or health service delivery. Poorly resources staffing is inadequate to effectively manage large, often remote protected areas. Increasingly, global climate change is a main driver Bangladesh's protected forest areas. Sea level rise and increased salinity is likely changing the habitat structure of the Sundarbans mangrove forest, drawing more salt-tolerant tree species deeper inland. Increased incidence of cyclones and other natural disasters is leading to more significant tree loss and subsequent vegetative change. Change in temperature and rainfall seasonality is likely impacting forest and wetland flora and fauna resources, exacerbating the negative impact of ongoing protected area encroachment and weakening the forest ecosystems to adapt and bounce back. There are a number of secondary drivers associated with the primary drivers threatening protected forest area system which includes lack of awareness, lack of clear tenure for forest dependent communities and various limitations of government to effectively manage a sprawling and often isolated protected forest area system. Management strategies yet addressing secondary drivers without addressing the underlying primary drivers is inefficient in the short run and ineffective in the long run. Only by addressing primary drivers as they relate to overall development and global climate change strategies, Bangladesh's protected forest area system can contribute resilience, sustainability and adaptation. Collaborative management system (Co-management) offers a management paradigm that can clearly address the primary drivers currently threatening the conservation of forest ecosystems of Bangladesh, turning threats into opportunities.

\section{Forest Management Techniques Recommended}

- Restoration and conservation of all remaining natural forests and constituent biodiversity in the Protected Areas can be done by assisting natural regeneration and enrichment planting of native species in the core zones. Target species will be propagated along with accompanying species, in a manner consistent with a restoration or rehabilitations plan and the broader, comprehensive co-management model and landscape approach to protected area management. In this way natural regeneration, species diversity and growth of the trees take place without destruction by people. Key habitats will begin to be restored and rehabilitated; degradation will be slowed, halted or reversed to the extent feasible period. As a result biodiversity is conserved, the productivity of forest is increased and ecosystem services are protected and enhanced. Bangladesh has developed effective co-management approaches in both forest and wetland ecosystems. Based on the positive results of the pilot project called 'Nisorgo Support Project', the co-management approach is now being adopted in all the 28protected areas (i.e. national parks and wildlife sanctuaries) of Bangladesh. In the co-management model, the management of a protected area is vested to a local co-management council (CMC) composed of representatives of local communities, relevant government line agencies and local government bodies including the local member of the parliament and the Divisional Forest officer as advisers. The forest officer in charge of the respective forest area act as the member secretary of the executive committee of the CMC. The CMC and technical experts of the forest department jointly develop a management plan for the protected area and its surrounding landscape which include aspects of forest protection, biodiversity conservation and social forestry activities in the buffer zone. Community patrol groups involving poor forest dependent people are established for patrolling the forests jointly with forest guards of the forest department. Key to effective co-management in 
Bangladesh is the rapid and significant demonstration of livelihoods benefits for poor people living adjacent to and dependent on forest. Such benefits can be generated from:

- $\quad$ sustainable development initiatives based on the intensification of economic activities in the landscape beyond the protected areas.

- effective conservation and restoration of protected areas through ecotourism development or social forestry activities.

- improved and enhanced environmental services from conserved protected areas including increased fish catch from wetland protected areas, improved access to stabilized water resources from well managed forest areas, sharing of payments for environmental services possibly from carbon sequestration and water resource management.

- Monocultures of exotic tree species can be converted into natural and man-made regeneration of indigenous species by gradually opening the top canopy. Proportion of exotic species which are not suitable for wildlife will gradually be reduced by following subsidiary silvicultural operations such as cleaning, climber cutting and freeing of natural regeneration from suppression. This will encourage natural regeneration of indigenous trees, shrubs, herbs and palatable grasses. Canopy opening will be done in small but irregular plots of say 2-4 ha, staggered to minimize disturbance to wildlife and its habitat (mosaic pattern of opening will provide better ground light penetration for natural regeneration). No canopy opening will be undertaken near waterbodies in order to avoid soil erosion. At least 50-100 trees/ha will be retained along with all the existing natural regeneration and advance growth. Marking of trees will be done after monsoon rains are over and felling operations completed by February. After felling, the first year will be devoted for obtaining natural regeneration. During the second year suitable gaps will be identified for raising enrichment plantations of indigenous fruit bearing shrubs/trees (suitable for wildlife) and palatable grasses.

- Woodlot plantations in degraded forestland can be established. Agro-forestry in the encroached land and strip plantation in the marginal land are important components in afforestation program to combat deforestation and forest degradation. Participatory benefit sharing agreement needs to be developed which requires beneficiaries to take a continuing role in conservation of the forest area, and that results in slowing down the degradation in landscape around degraded forests.

\section{Way Forward}

Vital life supporting and provisional role of forest ecosystems needs to be properly understood by policy makers in order to be mainstreamed in the national planning and decision making. Forests should no more be treated as revenue generators because substantial benefits of forests are due to their existence value in terms of services and functions they provide. Due to failure in valuing intangible socio-economic benefits of forests, their significant contribution in social welfare has not yet been captured. This means more research is needed in quantifying and monetizing vital values and services of forests to local community and beyond.

To conserve forests we must give their owners or users incentives to conserve them. We must make conservation more attractive than any other uses. Conserving healthy forests (not necessarily "untouched" forests) must be more attractive than clearing them to plant coffee, bananas or cocoa or raise cattle. Recently introduced payment to eco-system service' mechanism in some countries should be extended further and international community should come forward in this regard.

Conservation area management proved as efficient, successful and cost-effective tool for ecosystem conservation. However increasing the protected area network and improving management techniques are essential to enhance the resilience of ecosystem to climate change and safeguard vital ecosystem services. Carbon trading opportunities should also be perused for added benefit.

The current state of forest management research needs strengthening, particularly in view of significant global interest that has generated recently due to climate change functions and services of forests ecosystems.

Trans-boundary initiatives are required to manage the ecosystems efficiently. Cooperation and knowledge sharing among upstream and downstream countries could address the existing food, water, energy and economic crisis faced by the countries in Asia.

\section{REFERENCES}

[1] Ali, M.E., 2002b. Transfer of Sustainable Energy Technology to Developing Countries as a Means of Reducing Greenhouse Gas Emission - the Case of Bangladesh: Review of Relevant Literature, Discussion Paper No. 02.08 ed. Department of Applied and International Economics, Massey University, New Zealand (32 p.).

[2] Biswas, Shampa. 2007. Evaluating management strategies of integrated water resource management - a case study on Chittagong Hill Tracts (CHTs), Bangladesh. Mountain Forestry Universitätfür Bodenkultur BOKU-University of Natural Resources and Applied Life Sciences, Vienna.

[3] Brauman, K. A., G. C. Daily, T.K. Duarte, and H.A. Mooney. 2007. The Nature and Value of Ecosystem Services: Highlighting Hydrologic Service. Annual Review of Environment and Resources 32:67-98.

[4] Casemus, R, F. J. Escobedo, D. McLaughlin and A. 
Abd-Elrahman 2014. Analyzing trade-offs synergies, and drivers among timber Production, carbon sequestration, and water yield in Pinuselliotii forests in Southeastern USA. Forests 2014, 5, 1409-1431; doi: 10.3390/f5061409.

[5] Farber S. C., Robert C., and Matthew A. W. 2002.Economic and ecological concepts for valuing ecosystem services. Ecological Economics 41 (2002) 375-392. www.elsevier.co $\mathrm{m} /$ locate/ecolecon

[6] Forest Department 2010. National Report to the Ninth Session of the United Nations Forum on Forests.

[7] Gamborg, C., and J. B. Larsen. 2003. 'Back to nature'-a sustainable future for forestry? Forest Ecology and Management 179:559-571.

[8] Gregersen, H.M., Arnold, J.E.M., Lundgren, A.L. and Contreras-Hermosilla, A. 1995. Valuing forests: context, issues and guidelines. FAO Forestry Paper 127. Food and Agricultural Organization of the United Nations, Rome.

[9] Hunter, M. L. 2001.Maintaining biodiversity in forest ecosystems. Cambridge University Press, Cambridge, UK. http://dx.doi.org/10.1017/CBO9780511613029

[10] Kengen S. (1997): Forest Valuation for Decision Making Lessons of experience and proposals for improvement, FAO, Rome.

[11] MOEF, 2006. National Biodiversity Strategy and Action Plans. Ministry of Environment and Forests, Dhaka, Bangladesh.

[12] MOEF, 2009. Bangladesh Climate Change Strategy and Action Plan 2009. Ministry of Environment and Forests,
Government of People's Republic of Bangladesh, Dhaka, Bangladesh.

[13] Munasinghe, M. 1993. Environmental economics and biodiversity management in developing countries. Ambio 22(2-3): 126-135.

[14] Rodríguez, J.P., T.D. Beard Jr., E. M. Bennett, G.S. Cumming, S.J. Cork, J. Agard, A. P. Dobson, and G.D. Peterson. 2006. Trade-offs across Space, Time, and Ecosystem Services. Ecology and Society 11(1):28.

[15] Roy, M. K. Nishorgo Support project: Designing a Co-management Model for the Protected Areas of Bangladesh. In: Protected Area Management Program of Bangladesh. Forest Department, Ministry of Environment and Forests, People's Republic of Bangladesh.

[16] Seymour, R. S., and M. L. Hunter. 1999. Principles of ecological forestry. Pages 22-61 in M. Hunter, editor. Maintaining biodiversity in forested ecosystems. Cambridge University Press, Cambridge, UK. http://dx.doi.org/10.1017/ CBO9780511613029.004

[17] Smith, K.R. 2002. Indoor air pollution in developing countries: Recommendations for research. Indoor air 12:198-207.

[18] Stein, T.; Kil, N.; Frank, A.; Adams, A.E.; Adams, D.C.; Escobedo, F.J. Public land management agencies' and nonindustrial private forest landowners' perceptions about ecosystem services, University of Florida-IFAS, 2013. Available online: https://edis.ifas.ufl.edu/fr380 (accessed on 11June 2014). 